Лонькин Александр Петрович, студент, Саратовский государственный аграрный университет имени Н.И. Вавилова. Россия.

Кириченко Андрей Владимирович, аспирант кафедры «Техносферная безопасность и транспортно-технологические машины», Саратовский государственный аграрный университет имени Н.И. Вавилова. Россия.

Соловьев Владимир Александрович, асnирант кафедры «Строительство, теплогазоснабжение и энергообеспечение», Саратовский государственный аграрный университет имени Н.И. Вавилова. Россия.

410056, г. Саратов, ул. Советская, 60.

Тел.: (8452) 74-96-56.

Ключевые слова: дождевальная машина; полив; напряжение; электробезопасность; щит управления; реле; сопротивление проводника.

\title{
IMPROVING THE EFFICIENCY OF THE CONTROL SYSTEM OF ELECTRIFIED SPRINKLING MACHINE
} OF CIRCULAR ACTIONS «CASCADE»

Abdrazakov Fyarid Kinzhaevich, Doctor of Technical Sciences, Professor, Head of the chair "Construction, Heat and Gas Supply and Energy Supply”, Saratov State Agrarian University named after N.I. Vavilov. Russia.

Zhuravleva Larisa Anatolievna, Candidate of Technical Sciences, Associate Professor of the chair "Technosphere Safety and Transport-technological Machines Saratov State Agrarian University named after N.I. Vavilov. Russia.

Lonkin Alexander Petrovich, Student, Saratov State Agrarian University named after N.I. Vavilov. Russia.

Kirichenko Andrey Vladimirovich, Post-graduate Student of the chair "Technosphere Safety and Transport-technological Machines Saratov State Agrarian University named after N.I. Vavilov. Russia.
Solovyov Vladimir Alexandrovich, Post-graduate Student of the chair "Technosphere Safety and Transport-technological Machines Saratov State Agrarian University named after N.I. Vavilov. Russia.

Keywords: sprinkling machine; irrigation; voltage; electrical safety; control board; relays; resistance of the conductor.

The article discusses the structure and operation of modern control systems of sprinkler machine "CASCADE", the possibility of remote GSM-control of equipment, the elements of the calculation of the safety of electrical equipment.

\section{БОйков Василий Михайлович, Саратовский государственный аграрный университет} имени Н.И. Вавилова

СТАРЦЕВ Сергей Викторович, Саратовский государственный аграрный университет имени Н.И. Вавилова

ПАВЛОВ Андрей Владимирович, Саратовский государственный аграрный университет имени Н.И. Вавилова

НЕСТЕРОВ Евгений Сергеевич, Саратовский государственный аграрный университет имени Н.И. Вавилова

ЛАВРЕНТЬЕВ Алексей Васильевич, Саратовский государственный аграрный университет имени Н.И. Вавилова

Используя техническую характеристику прицепного лемешно-отвального плуга ПБС-10П и результаты испытаний плугов серии ПБС на ФГБНУ «Поволжская машиноиспытательная станиия», результаты испытаний тракторов лабораторией Nebraska Tractor Test США установлена величина крюкового усилия тракторов John Deer 9120 (196 кBm), New Holland $9282(175 \mathrm{\kappa Bm})$, Versatile 375 (268 $\mathrm{\kappa Bm})$, Case Magnum $340(251 \mathrm{kBm})$, Challenger MT $835(267 \mathrm{\kappa Bm})$, Fendt $926(200 \kappa \mathrm{km})$, Massey Fergusson $8480(200 \kappa \mathrm{km})$ и тягового сопротивления прицепного плуга ПБС-10П на соответствующих скоростях движения, определены аналитические зависимости крюкового усилия тракторов и тягового сопротивления плуга от скорости движения. Графоаналитическим методом расситаны оптимальные эксплуатационные показатели скомплектованных пахотных агрегатов и дана их сравнительная теоретическая оценка по производительности на основной обработке почвы в разных условиях. Представлены результаты экспериментальных исследований пахотного агрегата Cаsе Маgпит 340+ПБС-10П в условиях хозяйства Саратовской области и проверена сходимость полученных теоретических и экспериментальных исследований.

Введение. Для основной обработки почвы больших площадей в короткие сроки необходимо значительно наращивать производительность пахотных работ.
При нехватке отечественных тракторов Российская Федерация в большом количестве производит закупки иностранных энергонасыщенных тракторов большой мощности в США таких 
компаний, как FGCO (Fendt, Challenger, Maasei Fergusson, Case IH), John Deer, в Евросоюзе (Claas, New Holland), Versatile (Канада). С каждым годом количество таких тракторов увеличивается, в 2017 г. объем продаж тракторов составил 26423 ед., из которых только 2410 тракторов российских марок. По отношению к 2016 г. их доля на рынке снизилась с 13,5 до 9,1 \% [4].

Для повышения производительности основной отвальной обработки почвы в ФГОУ ВО Саратовский ГАУ был разработан прицепной отвальный плуг общего назначения ПБС-10П (рис. 1) для агрегатирования с тракторами мощностью 200250 кВт. Техническая характеристика плуга представлена в таблице.

Техническая характеристика плуга ПБС-10П

\begin{tabular}{|l|c|}
\hline \multicolumn{1}{|c|}{ Показатели } & Значение \\
\hline Ширина захвата, м & 6,0 \\
\hline Рабочая скорость, км/ч & До 12 \\
\hline Глубина обработки, см & До 30 \\
\hline Количество корпусов, ед. & 10 \\
\hline Ширина захвата корпуса, см & 60 \\
\hline Масса, кг & 4200 \\
\hline Производительность, га/ч & $4,5-5,6$ \\
\hline Габаритные размеры, мм & \\
длина & 12088 \\
ширина & 5990 \\
высота & 1762 \\
\hline Материалоемкость, кг/м & 786 \\
\hline
\end{tabular}

В этой связи оценка эксплуатационных показателей пахотных агрегатов, состоящих из иностранных тракторов мощностью 200-275 кВт и прицепного плуга ПБС-10П, обладает актуальностью и имеет практическое значение.

Цель работы - дать сравнительную оценку пахотных агрегатов, состоящих из прицепного плуга ПБС-10П и наиболее распространенных тракторов иностранного производства в Российской Федерации мощностью 200-275 кВт, по эксплуатационно-технологическим показателям для рационального использования на основной обработке почвы. Проверить сходимость полученных теоретических и экспериментальных результатов исследования пахотных агрегатов.

В основу достижения поставленной цели положены результаты испытания тракторов лабораторией Nebraska Tractor Test США [6] и плугов серии ПБС на ФГБНУ «Поволжская машиноиспытательная станция», пос. Усть-Кинельский, Кинельский район Самарской области $[2,3]$.

Для достижения цели необходимо решить следующие задачи:

1) установить величину крюкового усилия трактора и тягового сопротивления прицепного плуга на соответствующих скоростях движения;

2) определить аналитические зависимости крюкового усилия трактора и тягового сопротивления прицепного плуга от скорости движения;

3) графоаналитическим методом определить оптимальные эксплуатационные показатели пахотных агрегатов;

4) дать сравнительную оценку пахотных агрегатов по их производительности.

Методика исследований. Для решения поставленных задач использовали: 1) табличные данные результатов испытаний тракторов, аппроксимируя которые методом наименьших квадратов с величиной достоверности $R^{2}=0,991$, получили эмпирические зависимости крюкового усилия трактора при работе на стерневом фоне от скорости движения агрегата (при $N_{\text {кр }}=N_{\text {крmax }}$ );2) данные испытаний плугов серии ПБС на Поволжской МИС при обработке почв, характеризующихся по типу и гранулометрическому составу как чернозем обыкновенный среднесуглинистый. В экстремальных условиях влажность почвы составляла 8,0-15,3 \%, твердость почвы 1,9-5,1 МПа. При агротехнически допустимых условиях влажность составляла 18,0-22,0 \%, твердость почвы 1,9-3,1 МПа. Установочная глубина обработки почвы плугом в этих условиях составляла 21 и 25 см.

Результаты исследований. Для проведения теоретических исследований, используя результаты испытаний тракторов в лаборатории Nebraska Tractor Test США, широко применяемых в РФ, в диапазоне мощностей 175-275 кВт были приняты следующие марки тракторов: 1) John Deer 9120 (196 кВт), 2) New Holland 9282 (175 кВт), 3) Versatile 375 (268 кВт), 4) Case Magnum 340 (251 кВт), 5) Challenger MT 835 (267 кВт), 6) Fendt 926 (200 кВт), 7) Massey Fergusson 8480 (200 кВт). На основании аппроксимации результатов испытаний тракторов были получены сле-

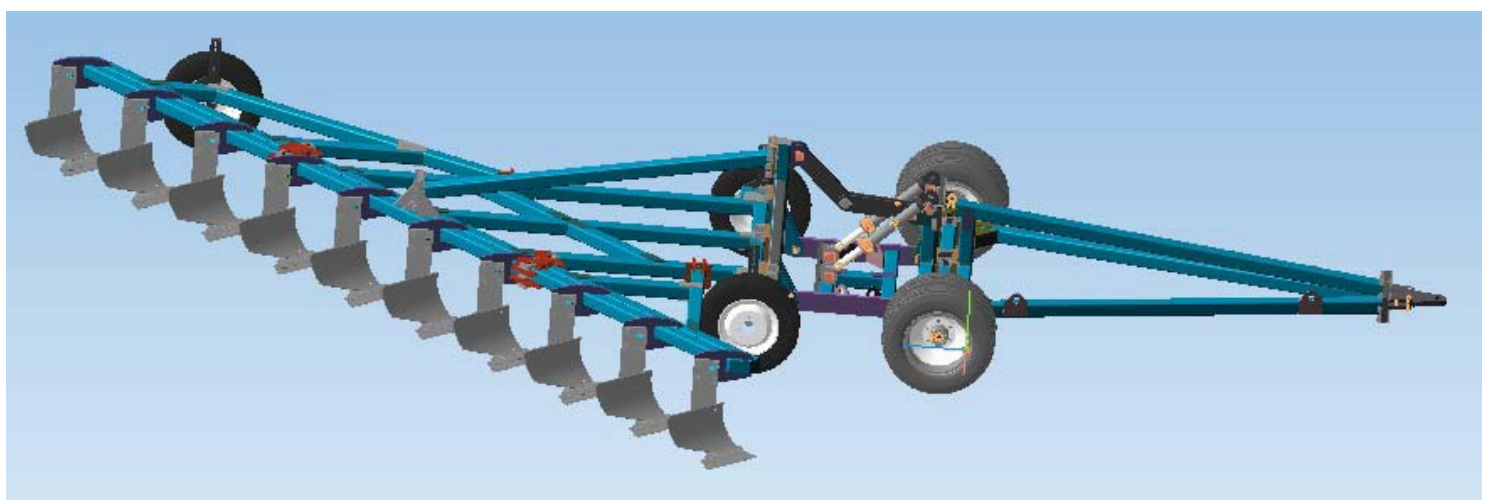


дующие зависимости крюкового усилия трактора от скорости движения:

1) $P_{\mathrm{\kappa p}}=15,466 \vartheta_{\mathrm{T}}^{2}-111,81 \vartheta_{\mathrm{T}}+247,24$;

2) $P_{\text {кр }}=8,8863 \vartheta_{\mathrm{T}}^{2}-72,571 \vartheta_{\mathrm{T}}+191,81$;

3) $P_{\text {кр }}=13,611 \vartheta_{\mathrm{т}}^{2}-106,15 \vartheta_{\mathrm{т}}+266,58$;

4) $P_{\text {кр }}=6,4821 \vartheta_{\mathrm{T}}^{2}-63,273 \vartheta_{\mathrm{T}}+194,91$;

5) $P_{\mathrm{kp}}=13,27 \vartheta_{\mathrm{T}}^{2}-103,98 \vartheta_{\mathrm{T}}+253,51$;

6) $P_{\mathrm{кр}}=-2,0748 \vartheta_{\mathrm{T}}^{2}-11,959 \vartheta_{\mathrm{T}}+108,11$;

7) $P_{\text {кр }}=5,8704 \vartheta_{\mathrm{T}}^{2}-54,944 \vartheta_{\mathrm{T}}+167,48$,

где $P_{\text {кр }}$ - крюковая сила трактора, кН; Э рость движения трактора, м/с.

На базе полученных аналитических выражений построен график изменения крюкового усилия трактора от скорости движения (рис. 2).

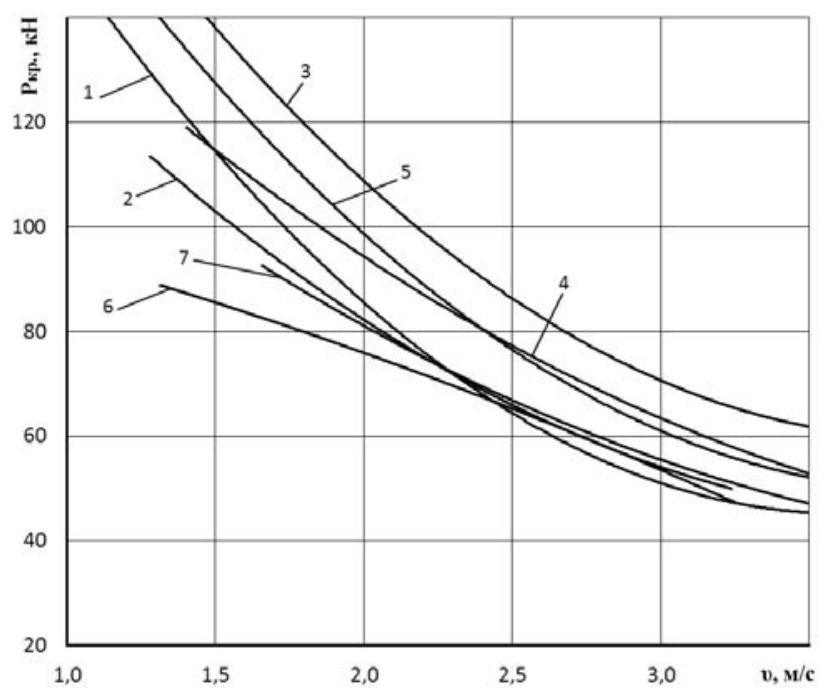

Рис. 2. Зависимость крюкового усилия трактора от скорости движения: 1 - John Deer 9120; 2 - New Holland 9282; 3 - Versatile 375; 4 - Case Magnum 340; 5 - Challenger MT 835; 6 - Fendt 926; 7 - Massey Fergusson 8480

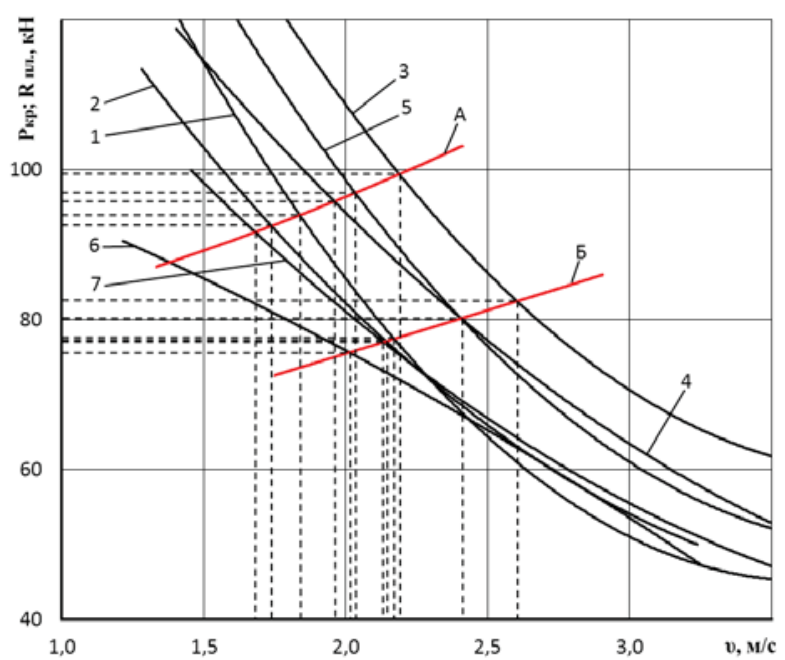

$a$
Анализ зависимостей (см. рис. 2) показывает, что крюковое усилие трактора при увеличении скорости движения изменяется по нелинейной закономерности. При этом крюковое усилие тракторов имеет различную величину.

На основании аппроксимации полученных данных при энергетической оценке плугов серии ПБС были получены следующие зависимости тягового сопротивления плуга от скорости движения при работе плуга:

$$
\begin{gathered}
R_{\Pi}^{\mathrm{A}}=2,2928 \vartheta_{\Pi}^{2}+6,3522 \vartheta_{\Pi}+74,531 ; \\
R_{\Pi}^{\mathrm{b}}=0,1 \vartheta_{\Pi}^{2}+11,128 \vartheta_{\Pi}+52,798 ; \\
R_{\Pi}^{\mathrm{B}}=1,9319 \vartheta_{\Pi}^{2}+5,4568 \vartheta_{\Pi}+63,304 ; \\
R_{\Pi}^{\Gamma}=0,085 \vartheta_{\Pi}^{2}+9,4587 \vartheta_{\Pi}+44,879,
\end{gathered}
$$

где $R_{\text {п }}^{\mathrm{A}}, \mathrm{R}_{\text {п }}^{\mathrm{5}} R_{\text {п, }}^{\mathrm{B}} R_{\text {п }}^{\text {г }}$ - тяговое сопротивление плуга, кН; $\vartheta_{\text {п }}$ - скорость движения плуга, м/с.

Известно [1], что при движении пахотного агрегата должно выполняться следующее условие (3):

$$
P_{\text {кр }}=R_{\text {п и }} \vartheta_{\text {т }}=\vartheta_{\text {п }} \text {. }
$$

Решение уравнений (1) и (2) с учетом условия (3) графоаналитическим методом представлено на рис. 3 , а, б.

Из графиков видно, что в точках пересечения кривых зависимостей тягового сопротивления плуга А, Б, В, Г и крюкового усилия трактора будет выполняться условие (3). Следовательно, точки пересечения будут показывать оптимальную скорость движения пахотного агрегата.

Для определения теоретической производительности пахотных агрегатов принимали ширину захвата плуга 6 м (см. таблицу) и величины оптимальных скоростей движения пахотных агрегатов из графиков (см. рис. 3). На рис. 4 представлены диаграммы производительности пахотных агрегатов при глубине обработки почвы 21 и 25 cм.

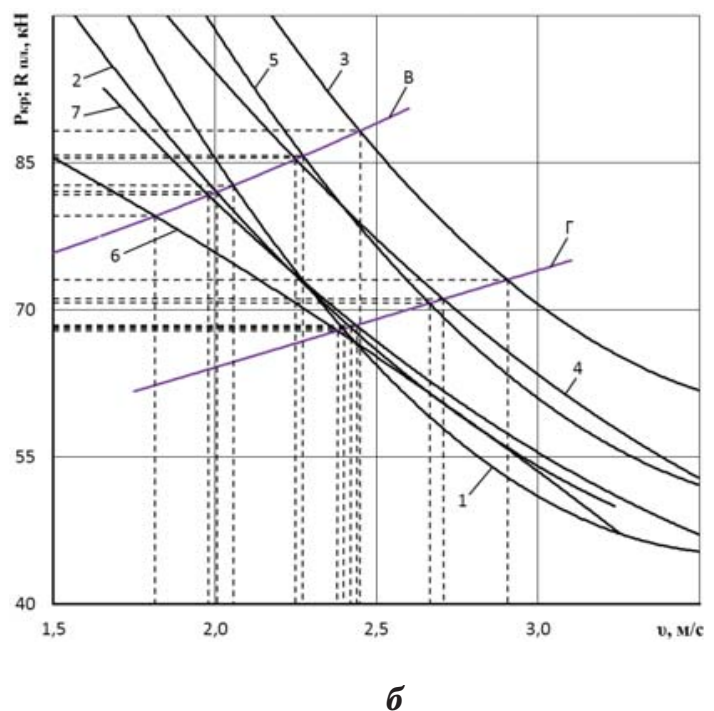

Рис. 3. Зависимость крюкового усилия трактора и тягового сопротивления плуга от скорости движения трактора при обработке почвы в экстремальных условиях (a) и почвы, соответствующей агротехническим требованиям (б): 1 - John Deer 9120; 2 - New Holland 9282; 3 - Versatile 375; 4 - Case Magnum 340; 5 - Challenger MT 835; 6 - Fendt 926; 7 - Massey Fergusson 8480 тракторы с плугом ПБС-10П 


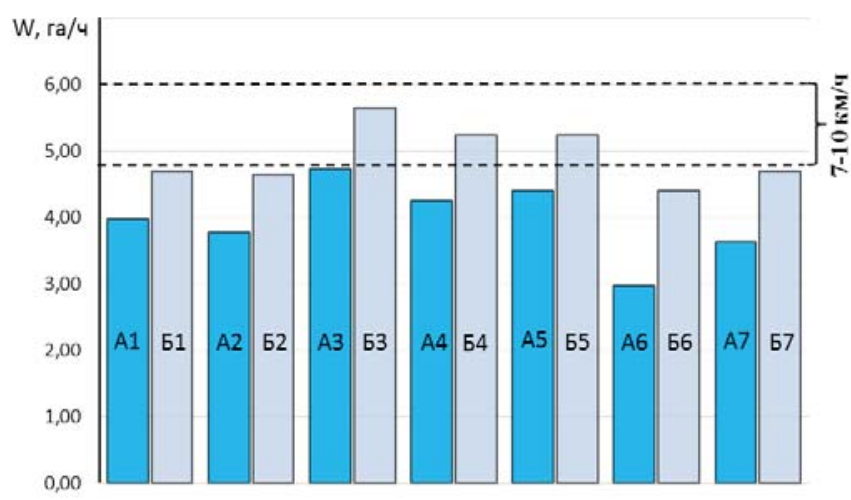

$a$

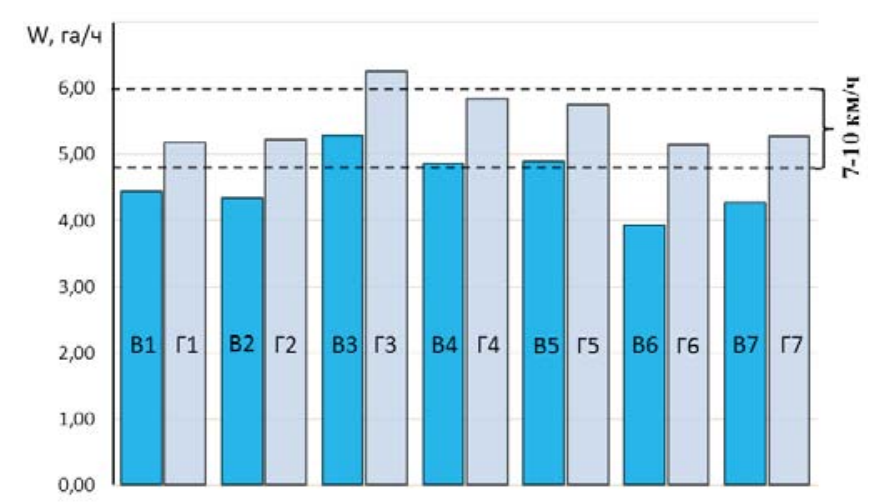

б

Рис. 4. Диаграмма производительности пахотных агрегатов при обработке почвы в экстремальных условиях (а) и почвы, соответствующей агротехническим требованиям (б): 1 - John Deer 9120; 2 - New Holland 9282; 3 - Versatile 375; 4 - Case Magnum 340; 5 - Challenger MT 835; 6 - Fendt 926; 7 - Massey Fergusson 8480

Заключение. Анализируя диаграммы (см. рис. 4, а, б), видно, что при уменьшении глубины обработки почвы с 25 до 21 см возрастает производительность пахотных агрегатов. Согласно агротехническим и эксплуатационнотехнологическим требованиям [5], предъявляемым к работе лемешно-отвальных плугов общего назначения, целесообразно обеспечить работу пахотного агрегата в диапазоне скоростей 7-10 км/ч. Этот диапазон выделен на диаграммах пунктирными линиями.

Из диаграммы (см. рис. 4, a) видно, что при обработке почвы, находящейся в экстремальных условиях, на глубину 25 см ни один из пахотных агрегатов не обеспечивает выполнение агротехнических требований в этом диапазоне скоростей. В этих же условиях пахотные агрегаты Б3, Б4, Б5, состоящие из тракторов Versatile 375, Case Magnum 340, Challenger MТ 835 и прицепного плуга ПБС-10П, могут выполнять обработку почвы на установочную глубину 21 см с качеством соответствующим агротехническим требованиям.

Из диаграммы (см. рис. 4, б) видно, что пахотные агрегаты В3, В4, В5, Г3, Г4, Г5, состоящие из тракторов Versatile 375, Case Magnum 340, Challenger MТ 835 и прицепного плуга ПБС-10П, при обработке почвы в условиях, соответствующих агротехническим требованиям, на глубину 21 и 25 см обеспечивают максимальную производительность в диапазоне скоростей 7-10 км/ч с качеством, удовлетворяющем агротехническим требованиям.

Для подтверждения полученных результатов теоретических исследований в ООО «Агроинвест» Марксовского района Саратовской области были проведены экспериментальные исследования пахотного агрегата, состоящего из трактора Case Magnum 340 и прицепного плуга ПБС-10П. Исследования проводили на почве чернозем обыкновенный среднесуглинистый, влажность почвы составляла 21-24 \%, твердость почвы 2,6-3,1 МПа. Установочная глубина обработки почвы составляла 25 см. Было определено, что при скорости движения пахотного агрегата 7,58,6 км/ч производительность агрегата составила 4,4-5,0 га/ч. Разница теоретической и экспериментальной производительности составляла 5$8 \%$ и в основном зависела от физико-механических свойств почвы.

Из вышеизложенного следует, что для повышения эффективности использования пахотных агрегатов с прицепным плугом ПБС-10П, для обработки почвы с высокими качественными показателями следует агрегатировать плуг следующими иностранными тракторами: Versatile 375 , Case Magnum 340 и Challenger MT 835.

\section{СПИСОК ЛИТЕРАТУРЫ}

1. Иофинов С.А., Лышико Г.П. Эксплуатация машиннотракторного парка. - 2-е изд., перераб. и доп. - М.: Колос, 1984. -351 c.

2. Протокол № 08-141-2011 (4010142) от 13 декабря 2011 года приемочных испытаний плуга ПБС-12П. Кинель, 2011. - 41 с.

3. Протокол № $08-26 П-2017$ от 8 ноября 2017 года приемочных испытаний плуга навесного ПБС-4К. Кинель, 2017. - 34 с.

4. Рекламно-информационный сборник. «СЕЛЬХОЗТЕХНИКА. Национальный аграрный каталог. Выпуск №17/1-е полугодие 2018г. - 46 с. - Режим доступа: http://www.selhoz-katalog.ru/about.php.

5. СТО АИСТ 10 4.6-2003 Стандарт организации. Испытания сельскохозяйственной техники. Машины почвообрабатывающие. Показатели назначения. Общие требования. - Режим доступа: http://www.snti.ru/ snips_sto-aist.htm

6. Institute of Agriculture and Natural Resources NEBRASKA TRACTOR TEST LABORATORY. - Режим доступа: https://tractortestlab.unl.edu/testreports.

Бойков Василий Михайлович, $\partial-p$ техн. наук, проф. кафедры «Проиессы и сельскохозяйственные машина в АПК», Саратовский государственный аграрный университет имени Н.И. Вавилова. Россия.

Старцев Сергей Викторович, $\partial-p$ техн. наук, проф. кафедры «Процессы и сельскохозяйственные машина в АПК», Саратовский государствен- 
ный аграрный университет имени Н.И. Вавилова. Россия.

Павлов Андрей Владимирович, канд. техн. наук, дочент кафедры «Технический сервис и технология конструкиионных материалов», Саратовский государственный аграрный университет имени Н.И. Вавилова. Россия.

Нестеров Евгений Сергеевич, канд. техн. наук, доиент кафедры «Проиессы и сельскохозяйственные машины в АПК», Саратовский государственный аграрный университет имени Н.И. Вавилова. Россия.
Лаврентьев Алексей Васильевич, аспирант кафедры «Процессы и сельскохозяйственные машины в АПК», Саратовский государственный аграрный университет имени Н.И. Вавилова. Россия.

410056, г. Саратов, ул. Советская, 60.

Тел.: (8452) 73-64-12.

Ключевые слова: пахотный агрегат; трактор; прицепной плуг; крюковое усилие; скорость движения; глубина обработки почвы; производительность.

\title{
RATIONAL COMBINING OF A TRAILED PLASTER WITH FOREIGN TRACTORS
}

Boykov Vasiliy Mihaylovich, Doctor of Technical Sciences, Professor of the chair "Processes and Agricultural Machinery in AIC", Saratov State Agrarian University named after N.I. Vavilov. Russia.

Startsev Sergey Viktorovich, Doctor of Technical Sciences, Professor of the chair "Processes and Agricultural Machinery in APIC", Saratov State Agrarian University named after N.I. Vavilov. Russia.

Pavlov Andrey Vladimirovich, Candidate of Technical Sciences, Associate Professor of the chair "Technical Service and Technology of Structural Materials", Saratov State Agrarian University named after N.I. Vavilov. Russia.

Nesterov Evgeniy Sergeevich, Candidate of Technical Sciences, Associate Professor of the chair "Processes and Agricultural Machinery in AIC", Saratov State Agrarian University named after N.I. Vavilov. Russia.

Lavrentyev Aleksey Vasilyevich, Post-graduate Student of the chair "Processes and Agricultural Machinery in AIC", Saratov State Agrarian University named after N.I. Vavilov. Russia.

Keywords: arable unit; tractor; trailed plow; hook force; speed; depth of tillage; productivity.
Using the technical characteristics of the PBS-10P trailed plow and plow and the results of the PBS series plow tests at the Povolzhskaya machine test station, the results of the tractor tests by the Nebraska Tractor Test USA laboratory established the hook force of the tractors John Deer $9120(196 k W)$, New Holland $9282(175 k W)$, Versatile 375 (268kW), Case Magnum 340 (251kW), Challenger MT 835 (267kW), Fendt 926 (200kW), Massey Fergusson $8480(200 \mathrm{~kW})$ and traction resistance of the trailing plow PBS-10P at the corresponding speeds, hook force tra and the traction resistance of the plow from the speed of movement. The optimum operational parameters of the completed arable aggregates were determined by graphoanalytical method and their theoretical comparative estimation on productivity on the basic soil cultivation in different conditions is given. The results of experimental investigations of the Case Magnum $340+$ PBS-10P arable aggregate in the conditions of the economy of the Saratov region are presented and the convergence of the theoretical and experimental studies obtained is checked.

\section{ХАРАКТЕРИСТИКА ПОСЛЕДСТВИЙ НЕНОРМИРУЕМЫХ УСЛОВИЙ ТРУДА В РАЗЛИЧНЫХ ПРОИЗВОДСТВАХ ЭНЕРГЕТИЧЕСКОГО ОБЕСПЕЧЕНИЯ И ПУТИ ИХ УЛУЧШЕНИЯ}

\author{
оРЛОВ Павел Сергеевич, Ярославская государственная сельскохозяйственная академия \\ ШКРАБАК Владимир Степанович, Санкт-Петербургский государственный аграрный \\ университет
}

ГОЛдОБИНА Любовь Александровна, Санкт-Петербургский горный университет СОЦКАЯ Ирина Марковна, Ярославская государственная сельскохозяйственная академия ШКРАБАК Роман Владимирович, Санкт-Петербургский государственный аграрный университет

Приведена характеристика последствий ненормируемых условий труда в различных производствах энергетического обеспечения предприятий и путей их улучшения. Обращено внимание на производственный травматизм и профессиональную заболеваемость. Даны краткие сведения о предложенных авторами решениях в части повышения эффективности и безопасности электроснабжения потребителей. Приведены результаты экспериментальных исследований предложенных рещений.

Введение. Общеизвестно, что условия труда определяющим образом влияют на уровень травматизма, профессиональной и производственно обусловленной заболеваемости работников всех видов экономической деятельности, включая агропромышленный комплекс (АПК).
Разнообразные виды производства и жизнедеятельности в целом генерируют свои вредности и опасности, которые в ряде случаев приводят к травмам и заболеваниям, к авариям, взрывам, чрезвычайным ситуациям. Характеризуя вредности отметим, что они сгруппированы, 